\title{
Increased dietary energy alters follicle dynamics and wave patterns in heifers
}

\author{
Rafael R Domingues $\circledast^{1,2,3}$, O J Ginther ${ }^{3,4}$, Mateus Z Toledo ${ }^{1}$ and Milo C Wiltbank ${ }^{1,2}$ \\ ${ }^{1}$ Department of Animal and Dairy Sciences, University of Wisconsin-Madison, Madison, Wisconsin, USA, \\ ${ }^{2}$ Endocrinology and Reproductive Physiology Program, University of Wisconsin-Madison, Madison, Wisconsin, USA, \\ ${ }^{3}$ Eutheria Foundation, Cross Plains, Wisconsin, USA and ${ }^{4}$ Department of Pathobiological Sciences, School of \\ Veterinary Medicine, University of Wisconsin-Madison, Madison, Wisconsin, USA
}

Correspondence should be addressed to M C Wiltbank; Email: wiltbank@wisc.edu

\begin{abstract}
Understanding the impacts of nutrition on reproductive physiology in cattle are fundamental to improve reproductive efficiency for animals under different nutritional conditions. Starting on Day 0 (day of ovulation) until next ovulation, Holstein heifers ( $n=24)$ were fed: low energy diet (ad libitum grass hay; LED) and high energy diet (ad libitum grass hay + concentrate supplement; HED). Heifers on HED gained more weight (average daily gain: $0.824 \pm 0.07 \mathrm{vs} 0.598 \pm 0.09 \mathrm{~kg} / \mathrm{day}$ ) and had increased insulin concentrations. The dominant follicle of wave 1 in HED had greater growth rate overall from Days 0 to 8 and on Days 6-7 and 8-9 and started atresia later. The dominant follicle of wave 2 in HED had greater growth rate overall from Day 9 to 18 and on Days 14-15 and 15-16. In two-wave patterns, there was no difference in estradiol or progesterone concentrations but concentrations of FSH were lower in HED on Days 15 and 16. Estradiol concentrations increased earlier in two-wave patterns in association with earlier luteolysis. The frequency of two follicular waves was greater in HED than LED $(11 / 12$ vs $6 / 11 ; 92.7 \%$ vs $54.5 \%)$. In conclusion, an acute increase in dietary energy altered not only growth rate of the dominant follicle but also follicular wave pattern in heifers by increasing frequency of two follicular waves. The hypotheses were supported that an acute increase in dietary energy (1) prolongs growth period of dominant follicles and (2) alters follicular wave pattern in heifers.

Reproduction (2020) $\mathbf{1 6 1}$ 943-953
\end{abstract}

\section{Introduction}

Follicular wave dynamics have been studied for several decades in numerous species and are crucial for a better understanding of basic reproductive physiology and development of assisted reproductive technologies in humans and domestic animals. During each follicular wave in cattle, a cohort of several follicles emerge and grow in a common growth phase until follicle deviation when typically a single selected follicle continues to grow becoming a dominant follicle (DF) while others (subordinate follicles) regress in diameter by undergoing atresia (Ginther 2016). The endocrine dynamics of follicle development and selection are finely regulated (Ginther 2016, Gomez-Leon et al. 2019). An FSH surge stimulates follicle emergence and growth while growing follicles secrete inhibitory factors (inhibin, estradiol) that have a negative feedback on FSH concentrations. The selected DF continues to grow in the basal FSH environment and secretes increasing amounts of estradiol (E2) that maintain basal FSH concentrations preventing emergence of a new follicular wave (Adams et al. 1992, Ginther et al. 2013).
When the DF loses dominance and E2 secretory capacity, FSH concentrations increase and stimulate emergence of the next follicular wave.

During an interovulatory interval (IOI), two or three follicular waves develop in heifers (Ginther et al. 1989, Fortune 1993, Adams et al. 2008). The first follicular wave (wave 1) is typically anovulatory and the last follicular wave is ovulatory (Ginther et al. 1989, Jaiswal et al. 2009, Forde et al. 2011). Therefore, the second follicular wave (wave 2) will be ovulatory and anovulatory in two and three-wave IOI, respectively. Several research groups have investigated the incidence of two and three-wave patterns in cattle, however, the determinants of the follicular wave patterns are not adequately defined. The complexity of the determinants of the number of follicular waves during an $\mathrm{IOI}$ is further clouded by the range in incidence of two and three waves reported in different studies (Ginther et al. 1989, Taylor \& Rajamahendran 1991, Fortune 1993). Three-wave patterns are typically associated with earlier emergence of wave 2, smaller diameter of the preovulatory follicle, later luteolysis, and longer IOI (Ginther et al. 1989, Fortune 1993, Jaiswal et al. 2009). 
Nutritional status clearly affects reproductive physiology and performance in cattle (Gong 2002, Sartori et al. 2013, Ferraretto et al. 2014). The most dramatic effect of nutrition on ovarian function is known as nutritional anestrous, that is, a prolonged period of dietary restriction leads to cessation of estrous cycles (Rhodes etal. 1995). Other effects of nutritional restriction include delayed onset of puberty (Cardoso et al. 2018), lower follicle growth rate, and smaller preovulatory follicle (Murphy et al. 1991, Mackey et al. 2000). In contrast, increased energy intake reduces number of small and large follicles, superovulatory response, and number of viable embryos in superovulated cows (Gong et al. 2002a).

A previous report speculated that the frequency of two and three-wave patterns was influenced by nutrition after beef heifers were fed different levels of dry matter intake for 5 weeks (Murphy et al. 1991). However, the limited number of animals per treatment group $(n=5$ to 7) precluded comprehensive interpretation of the effect of nutrition on follicular dynamics in heifers. A comprehensive understanding of the effects of nutrition on follicular wave dynamics could provide insights into implementing better reproductive strategies for animals under different nutritional conditions. Therefore, the present study investigated the effects of increased dietary energy during an IOI (approximately 21 days) on follicle development and dynamics in heifers. We hypothesized that an acute increase in dietary energy (1) prolongs the growth period of dominant follicles and (2) alters the follicular wave pattern in heifers.

\section{Materials and methods}

\section{Heifers and synchronization}

Holstein dairy heifers (Bos taurus) between 16 and 26 months of age and weighing $452 \pm 14 \mathrm{~kg}$ were studied in September and October in Wisconsin, USA (northern temperate zone). At the beginning of the experiment, body condition score was $2.96 \pm 0.05$ on a scale from one to five with 0.25 increments (Ferguson et al. 1994). The reproductive tracts were initially evaluated by transrectal ultrasonography and no apparent abnormalities were observed. The heifers were kept under natural light in open shelters and provided with ad libitum access to water, mineralized salt, and grass hay. Heifer management was done in accordance with the United States Department of Agriculture Guide for Care and Use of Agricultural Animals in Research and with an animal protocol that was approved by the Animal Care and Use Committee (IACUC) of the College of Agriculture and Life Sciences at the University of Wisconsin-Madison.

Heifers $(n=25)$ were synchronized with a 5-day CIDR-synch protocol with adaptations made in our laboratory as described (Domingues et al. 2020). Ultrasound scans were done daily for detection of ovulation (Day 0).

\section{Experimental design}

All heifers were fed grass hay throughout the entire synchronization and experimental protocol ad libitum. The same batch of Orchard grass hay $(85 \%$ dry matter (DM), 9.4\% crude protein (CP), and $67.2 \%$ amylase-treated neutral dietary fiber (aNDF) as percent of DM) was used throughout the entire experimental period. On Day 0, heifers were stratified by weight and randomly allocated into two groups: low energy diet (LED; ad libitum grass hay; $n=12$; one heifer was excluded therefore 11 heifers were used for statistical analyses) and high energy diet (HED; ad libitum grass hay + concentrate supplement; $n=13$ ). A concentrate supplement $75 \%$ ground dried corn, $20 \%$ soybean meal $48 \%$ $\mathrm{CP})$, and $5 \%$ molasses) was fed for HED to provide increased dietary energy. The concentrate supplement (3.1 kg as fed) was offered daily between 08:00 and 11:00 h (immediately after transrectal ultrasound scanning) throughout the studied IOI. Each heifer was individually housed for $20-40 \mathrm{~min}$ so that all the concentrate was consumed.

\section{Transrectal ultrasonic imaging}

Heifers were examined by transrectal ultrasonic imaging daily from Day 0 until the ovulation at the end of the IOI. An ultrasound instrument (Mindray M5, Nanshan, China) equipped with a 7.5-MHz transducer was used. Follicle diameter of all follicles greater than $4 \mathrm{~mm}$ was obtained from two perpendicular measurements of the antrum. The identity of all follicles greater than $4 \mathrm{~mm}$ was maintained as described (Ginther 1998). For comparisons of wave 1 between LED and HED, analysis of DF (DF1) development involved three periods: predominance ( 4 to $<10 \mathrm{~mm}$ ), postdominance $(\geq$ $10 \mathrm{~mm}$ ), and regression (negative growth rate as indicated by continuous decrease in follicle diameter). For wave 2, the DF (DF2) was compared during predominance and postdominance between LED and HED in two-wave patterns. Attaining 10 $\mathrm{mm}$ has been used to describe a follicle as dominant based on the acquisition of ovulatory capacity (Sartori et al. 2001). Bloodflow signals in the follicle wall were assessed in the preovulatory DF from the day of luteolysis (blood flow less than $20 \%$ of the $C L$ area) until the day before ovulation as described (Ginther 2007).

\section{Blood collection and hormone assays}

Blood samples were collected daily into heparinized tubes by venipuncture of the coccygeal vein immediately beforetransrectal ultrasonography and placed immediately into ice water until centrifugation (2000 $\boldsymbol{g}$ for $10 \mathrm{~min}$ ). Plasma was stored at $-20^{\circ} \mathrm{C}$ until assayed. Concentrations of FSH and progesterone (P4) were determined daily, concentrations of E2 were determined from Day 10 until ovulation, and concentrations of insulin were determined every 3 days. In addition, a blood sample was collected every 3 days at $6 \mathrm{~h}$ after concentrate feeding in HED and corresponding hour in LED for measurement of insulin and $\mathrm{P} 4$. Concentrations of FSH were determined by RIA as described (Adams et al. 1992). The intraassay CV, interassay $\mathrm{CV}$, and the sensitivity were $1.8 \%, 2.8 \%$, and $0.04 \mathrm{ng} / \mathrm{mL}$, respectively. 
Table 1 Mean \pm S.E.M for weight gain in heifers fed a low energy diet (LED) vs high energy diet (HED) during one interovulatory interval.

\begin{tabular}{lccc}
\hline & LED $(n=11)$ & HED $(n=13)$ & $\boldsymbol{P}$-value \\
\hline Weight before treatment $(\mathrm{kg})$ & $465.5 \pm 20.4$ & $441.3 \pm 18.6$ & 0.4 \\
Overall weight gain (21 days; kg) & $12.6 \pm 1.89$ & $17.3 \pm 1.47$ & 0.03 \\
Weight gain/day (kg) & $0.598 \pm 0.09$ & $0.824 \pm 0.07$ & 0.03 \\
Weight gain (21 days; \%) & $3.6 \pm 0.5$ & $5.4 \pm 0.4$ & 0.004 \\
\hline
\end{tabular}

Concentrations of P4 were determined by RIA (ImmuChem Coated Tube Progesterone 125I RIA Kit, MP Biomedicals, CA, USA) as described (Gomez-Leon et al. 2019). The intraassay CV, interassay $\mathrm{CV}$, and the sensitivity were $8.9 \%, 9.7 \%$, and $0.1 \mathrm{ng} /$ $\mathrm{mL}$, respectively. Concentrations of insulin were determined by commercial ELISA kit (Bovine Insulin ELISA, Mercodia, NC, USA), as described by the manufacturer. The intraassay $\mathrm{CV}$, interassay $\mathrm{CV}$, and the sensitivity were $6.0 \%, 6.7 \%$, and $0.08 \mathrm{ng} /$ $\mathrm{mL}$, respectively. Concentrations of $\mathrm{E} 2$ were determined by RIA (Ultra Sensitive Estradiol DSL-4800 Beckman Coulter, Prague, Czech Republic) as previously done in our laboratory (GomezLeón et al. 2020) with minor modifications: all samples had 500 $\mu \mathrm{L}$ double-extracted with $2.5 \mathrm{~mL}$ of methyl ter-butyl ether and, after extraction and complete evaporation, resuspension was made with $200 \mu \mathrm{L}$ of assay buffer. The intraassay CV, interassay $\mathrm{CV}$, and the sensitivity were $5.1 \%, 9.5 \%$, and $0.538 \mathrm{pg} / \mathrm{mL}$, respectively.

\section{Statistical analysis}

All statistical analyses were done with SAS (Version 9.4; SAS Institute Inc., NC, USA). The frequency of number of follicular waves between HED and LED was compared using Fisher's exact test. Weight gain was analyzed by one-tail $t$-test, follicle growth rate and insulin concentrations were analyzed by oneway ANOVA. Continuous data were analyzed with PROC MIXED. Studentized residuals with deviations from assumptions of normality (based on Shapiro-Wilk test) and/or homogeneity of variance were transformed to natural logarithms or ranks. When a main effect or interaction was significant, Tukey's HSD test was used for comparisons between groups within a day and between days within a group. A $P \leq 0.05$ indicated a difference was significant, and a $P>0.05$ and $\leq 0.1$ indicated that significance was approached. Data are presented as the mean \pm S.E.M.

\section{Results}

One heifer from the LED was removed from the experiment because of delayed wave 2 emergence (Day 14) accompanied by delayed peak FSH surge 2 (Day 14). All further analyzes were done with 11 heifers in LED and 13 in HED.

All heifers gained weight throughout the experimental period. The HED heifers gained $0.824 \pm 0.07 \mathrm{~kg} /$ day and the LED heifers gained $0.598 \pm 0.09 \mathrm{~kg} /$ day (Table 1). Overall, HED heifers gained 38\% more weight compared to LED throughout the experimental period.

Insulin concentrations for LED and HED averaged over days are shown (Fig. 1). Insulin concentrations were greater in HED $6 \mathrm{~h}$ after feeding the concentrate than LED and overall insulin concentrations were greater in HED than LED $(P=0.0002 ; 0.49 \pm 0.02$ vs $0.38 \pm 0.01$ $\mathrm{ng} / \mathrm{mL}$ ). For the LED, there was no difference in insulin concentrations between heifers with two or three-wave patterns before or $6 \mathrm{~h}$ after HED concentrate feeding $(P=0.3$; not shown).

The frequency of two and three-wave patterns in LED and HED is shown (Table 2). Overall, the frequency of two-wave patterns was greater in HED than LED $(P=0.048)$.

Dynamics of the DF of waves 1, 2, and 3 and their associated $\mathrm{FSH}$ and $\mathrm{P} 4$ profiles during $\mathrm{IOI}$ with two and three- waves from LED and HED are shown (Fig. 2). Diameters of DF1 and DF2 were not different between LED and HED for two-wave patterns during development of waves 1 and 2, respectively; only the main effect of day was significant. More comprehensive comparisons between HED and LED for waves 1 and 2 are shown below. Only one heifer in HED had three follicular waves which precluded further comparisons involving wave 3 dynamics between LED and HED. For LED with three- waves, the preovulatory DF of wave 3 (DF3) reached $6 \mathrm{~mm}$ on Day $16.4 \pm 0.4$. The maximum diameter of DF3 was $13.5 \pm 0.5 \mathrm{~mm}$ and occurred on Day $22.0 \pm 0.4$.

For FSH concentrations, there was only a main effect of day in two-wave patterns (Fig. 2). Mean FSH surge 2 peaked on Days 9 and 8 in two and threewave patterns, respectively. In three-wave patterns, mean FSH surge 3 peaked on Day 16. For two-wave patterns, concentrations of P4 were not different between LED and HED; only the main effect of day was significant (Fig. 2). The first significant decrease of

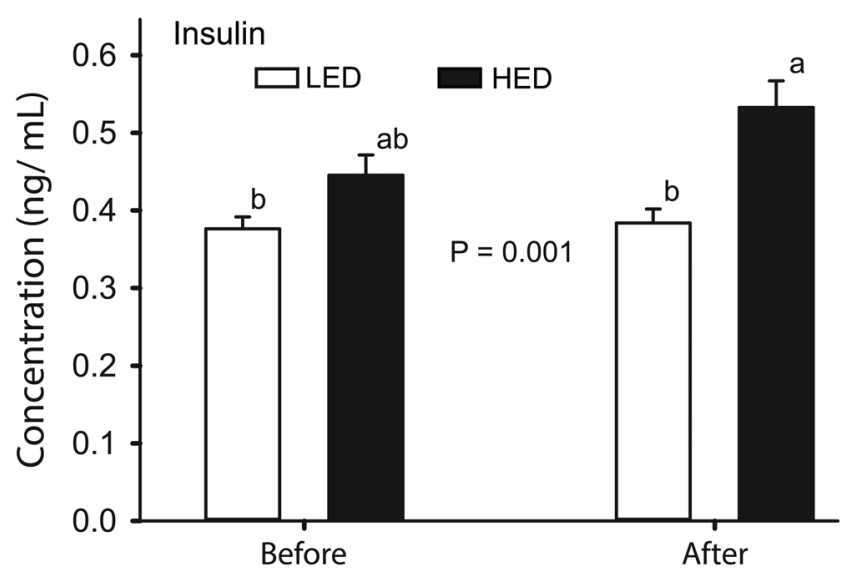

Figure 1 Mean \pm S.E.M. for concentrations of insulin averaged over days for heifers fed low energy diet (LED; $n=11$ ) vs high energy diet (HED; $n=13$ ) throughout an interovulatory interval. Blood samples were collected every 3 days before feeding (Before) and $6 \mathrm{~h}$ after (After) feeding concentrate supplement for HED and the

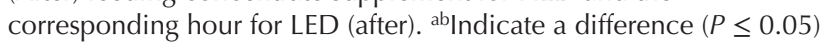
among groups. 
Table 2 Frequency of two and three follicular waves during an interovulatory interval in heifers fed low energy diet (LED) vs high energy diet (HED) during one interovulatory interval.

\begin{tabular}{lcc}
\hline & LED & HED \\
\hline 2 waves, $\%(n)$ & $54.5(6)$ & $92.3(12)$ \\
3 waves, \% $(n)$ & $45.5(5)$ & $7.7(1)$ \\
\hline
\end{tabular}

Fisher's exact test was used to compare the frequency of two vs three-wave patterns in LED and HED $(P=0.048)$.

mean P4 concentration occurred on Days 15 and 17 in two and three-wave patterns, respectively. From Days 0 to 13 (before luteal regression), concentrations of progesterone were not different between LED and HED (combined for two and three-wave patterns) before and $6 \mathrm{~h}$ after HED concentrate feeding; only main effect of day was significant (not shown).

For the LED, the growth dynamics of DF1 were not different between two and three-wave patterns, and therefore were combined for comparisons with DF1 from HED. The diameter of DF1 was not different between LED and HED throughout all periods of wave 1 development (predominance, postdominance and atresia); only the main effect of day was significant (Fig. 3). Daily follicle growth rate averaged over Days 0 to 8 (before follicle regression) approached being greater in HED vs LED groups $(P=0.099 ; 1.2 \pm 0.1$ vs $1.0 \pm 0.1$, respectively). The growth rate of DF1 in HED was significantly greater between Days 6 and 7 $(P=0.02)$ and approached significance between Days 8 and $9(P=0.07)$. The comparison of follicle growth rate between two consecutive days indicated that a significant decrease in growth rate occurred later in the HED (between Days 6-7 and 7-8) vs LED (between Days 5-6 and 6-7). Additionally, the mean Day of DF1 negative growth rate (follicle atresia) tended to be later $(P=0.06)$ in HED vs LED (Days $8.5 \pm 0.3$ vs $7.8 \pm 0.3$, respectively).

Differences in DF2 development, luteolysis, and IOI between two vs three-wave patterns and LED vs HED are shown (Table 3). The DF2 reached $6 \mathrm{~mm}$, dominance, and maximal diameter earlier in three vs two-wave patterns. A third follicular wave was associated with smaller maximum diameter of DF2, later luteolysis, and longer IOI. The interval from the end of luteolysis and ovulation was shorter $(P=0.02)$ in two $(3.1 \pm 0.2$ days averaged over HED and LED with two-waves) vs threewave $(4.4 \pm 0.5$ days $)$ patterns.

For two-wave patterns, the growth dynamics of ovulatory DF2 in LED and HED were not different during predominance (Days 9 to 13); only the main effect of day was significant (Fig. 4). During postdominance (Days 14-18), the main effect of day was significant and the group-by-day interaction approached significance; although DF2 diameter was not different between groups on each day. Daily follicle growth rate of DF2 averaged over Days 9-18 was greater in HED vs LED $(P=0.02$; $1.3 \pm 0.1$ vs $1.1 \pm 0.1$, respectively). The DF2 growth rate was greater for HED than LED between Days 14 and $15(P=0.05)$ and between Days 15 and $16(P=0.02)$. For FSH concentrations, there was only a main effect of day during predominance. During postdominance, main effects of group and day were significant. Concentrations of FSH were lower in HED vs LED overall during Days 14-18 (0.19 \pm 0.01 vs $0.27 \pm 0.03$ ng/mL, respectively). A separate analysis further indicated lower FSH concentrations in HED on Days $15(P=0.05)$ and $16(P=0.007)$. For concentrations of $\mathrm{E} 2$, there was only a main effect of day during postdominance.

Concentrations of E2 and P4 from Days 10 to 19 from two and three-wave patterns for LED and HED are shown (Fig. 5). For concentrations of E2, main effects of group and day were significant and a groupby-day interaction approached significance. Overall, concentrations of E2 were greater in two-wave patterns $(1.2 \pm 0.14 \mathrm{pg} / \mathrm{mL}$ averaged over HED and LED with two-waves) vs three-wave patterns $(0.31 \pm 0.07 \mathrm{pg} /$ $\mathrm{mL}$ ) from Days 10 to 19 . Mean peak concentration of E2 occurred on Day 17 (4.05 $\pm 0.65 \mathrm{pg} / \mathrm{mL})$ and 20 $(1.53 \pm 0.42 \mathrm{pg} / \mathrm{mL})$ in two and three-wave patterns, respectively. For concentrations of $\mathrm{P} 4$, the main effect of day and the group-by-day interaction were significant. Progesterone concentrations decreased earlier in
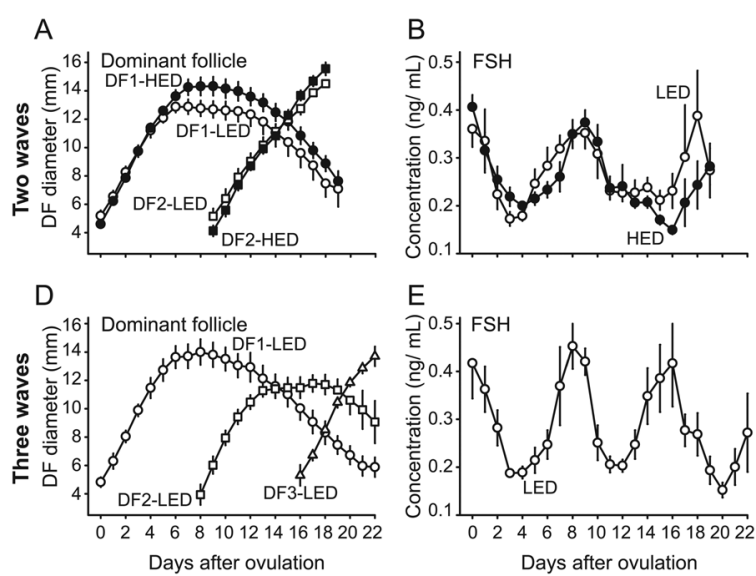

Days after ovulation
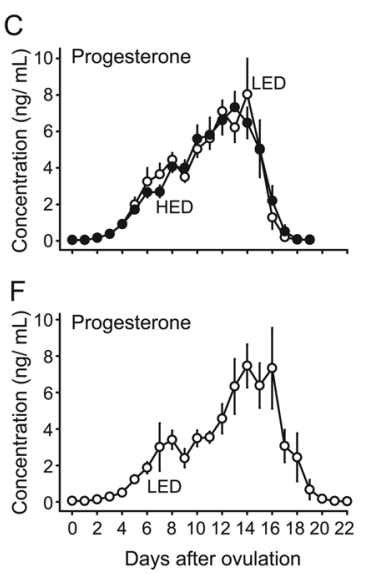

Figure 2 Mean \pm S.E.M. for dominant follicle (DF) diameter of waves 1, 2, and 3 (DF1, DF2, and DF3, respectively) (A and D) and concentrations of $\mathrm{FSH}(\mathrm{B}$ and $\mathrm{E})$ and progesterone ( $\mathrm{C}$ and $\mathrm{F}$ ) during interovulatory interval (IOI) of heifers fed low energy diet (LED; $n=6$ and 5 for two and three-wave pattern, respectively) vs high energy diet (HED; $n=12$ ) throughout an IOI. Only main effect of day was significant for all evaluated endpoints. 
Table 3 Mean \pm S.E.M for follicular wave two characteristics, measures of luteolysis, and interovulatory interval (IOI) in heifers with two vs three follicular waves fed low energy diet (LED) vs high energy diet (HED) during an IOI.

\begin{tabular}{|c|c|c|c|c|}
\hline & \multirow{2}{*}{$\begin{array}{c}\text { HED } \\
2 \text { waves } \\
\end{array}$} & \multicolumn{2}{|c|}{ LED } & \multirow[b]{2}{*}{$P$-value } \\
\hline & & 2 waves & 3 waves & \\
\hline Number of heifers & 12 & 6 & 5 & \\
\hline Day of DF2 closest to $6 \mathrm{~mm}$ & $10.3 \pm 0.3^{\mathrm{a}}$ & $9.8 \pm 0.3^{\mathrm{ab}}$ & $9.0 \pm 0.3^{b}$ & 0.04 \\
\hline Day of DF2 dominance ${ }^{\#}$ & $13.0 \pm 0.3^{\mathrm{a}}$ & $13.0 \pm 0.4^{\mathrm{a}}$ & $11.4 \pm 0.5^{b}$ & 0.03 \\
\hline DF2 maximal diameter (mm) & $15.5 \pm 0.4^{\mathrm{a}}$ & $14.5 \pm 0.1^{\mathrm{a}}$ & $12.0 \pm 0.5^{\mathrm{b}}$ & $<0.0001$ \\
\hline DF2 maximal volume $\left(\mathrm{mm}^{3}\right)$ & $1984.1 \pm 148.4^{\mathrm{aA}}$ & $1609.0 \pm 49.5^{\mathrm{aB}}$ & $935.0 \pm 124.2^{b}$ & 0.0004 \\
\hline Day of DF2 maximal diameter & $17.8 \pm 0.2^{\mathrm{a}}$ & $18.0 \pm 0.4^{\mathrm{a}}$ & $15.4 \pm 0.7^{\mathrm{b}}$ & 0.0003 \\
\hline Beginning of luteolysis* (day) & $14.7 \pm 0.3^{\mathrm{a}}$ & $14.5 \pm 0.2^{\mathrm{a}}$ & $17.2 \pm 0.6^{b}$ & 0.0005 \\
\hline End of luteolysis ${ }^{\ddagger}$ (day) & $16.2 \pm 0.3^{\mathrm{a}}$ & $16.2 \pm 0.3^{\mathrm{a}}$ & $18.6 \pm 0.4^{b}$ & 0.0002 \\
\hline Interovulatory interval (days) & $18.8 \pm 0.2^{\mathrm{a}}$ & $19.0 \pm 0.4^{\mathrm{a}}$ & $23.0 \pm 0.4^{b}$ & $<0.0001$ \\
\hline
\end{tabular}

"Day closest to $10 \mathrm{~mm}$; *Day before $50 \%$ decrease in P4; ${ }^{\ddagger}$ Day $P 4<1 \mathrm{ng} / \mathrm{mL}$; ${ }^{\mathrm{a}, \mathrm{b}}$ means within a row with different superscript letters are different $(P<0.05)$; ${ }^{\mathrm{A}, \mathrm{B}}$ means within a row with different superscript letters approach significance $(0.05<P \leq 0.1)$.
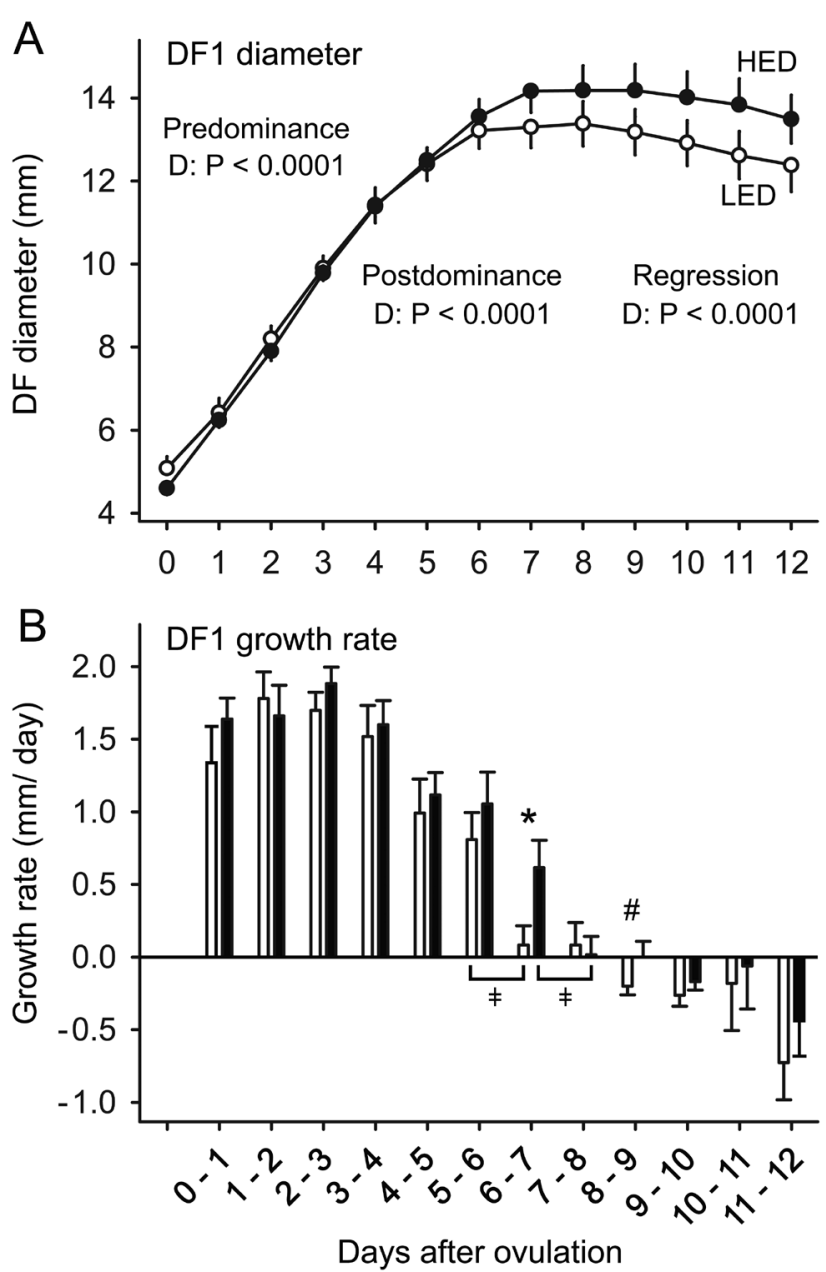

Figure 3 Mean \pm S.E.M. for diameter (A) and growth rate (B) of the dominant follicle of wave 1 (DF1) for heifers fed low energy diet (LED; $n=11$ ) and high energy diet (HED; $n=13$ ) throughout an interovulatory interval (IOI). For the LED, growth dynamics of DF1 were not different between two and three-wave patterns therefore data were combined. Diameter of DF1 was evaluated during predominance (4 to $<10 \mathrm{~mm}$; Days 0 to 3 ), postdominance ( $\geq 10 \mathrm{~mm}$; Days $4-8)$, and regression (negative growth rate; Days 9-12). *Indicates difference $(P<0.05)$ and \# indicates significance was approached $(0.05<P \leq 0.1)$ between groups. $₹$ indicates a difference $(P \leq 0.05)$ within a group over days. two-wave patterns. The day of beginning of luteolysis in each heifer is shown.

Dominant follicle dynamics and concentrations of E2 and $\mathrm{P} 4$ were normalized to the beginning of luteolysis (Day before $50 \%$ decrease in progesterone concentrations) (Fig. 6). The anovulatory DF2 from LED with three-wave patterns had significant growth (diameter increase) from 8 to 4 days before the onset of luteal regression and reached a plateau phase with no further increase in mean diameter thereafter. The ovulatory DF2 from HED and LED with two-wave patterns and the DF3 from LED with three-wave pattern had significant daily increase in diameter from emergence until ovulation. At the beginning of luteolysis, the mean follicle diameters were $11.7 \pm 0.5 \mathrm{~mm}$ for the ovulatory DF2 (averaged over HED and LED with twowave patterns), $11.4 \pm 0.6 \mathrm{~mm}$ for the anovulatory DF2 from LED with three-wave pattern, and $6.6 \pm 0.9 \mathrm{~mm}$ for the DF3 from LED with three-wave patterns.

Concentrations of E2 were not different between HED and LED before luteolysis (Fig. 6). From the beginning of luteal regression until 4 days after there were significant main effects of group and day. Concentrations of E2 were greater in two (combined for the HED and LED) vs three-wave patterns $(1.27 \pm 0.16$ vs $0.61 \pm 0.15 \mathrm{pg} / \mathrm{mL}$, respectively). Separate analysis further indicated greater concentrations of E2 in two-wave patterns $1(P=0.02)$ and $2(P=0.007)$ days after the beginning of luteolysis. Concentrations of $\mathrm{P} 4$ were not different in two vs threewave patterns and LED vs HED before and after the beginning of luteolysis; only the main effect of day was significant.

Percentage of follicle wall with blood flow signals was greater in the preovulatory DF2 for HED vs LED 2 and 1 days before ovulation (Fig. 7). Follicle blood flow on the day before ovulation was $28.8 \pm 4.3 \%$ for LED with three-wave pattern.

\section{Discussion}

Identifying the impacts of nutrition on follicle development and dynamics in cattle are fundamental 

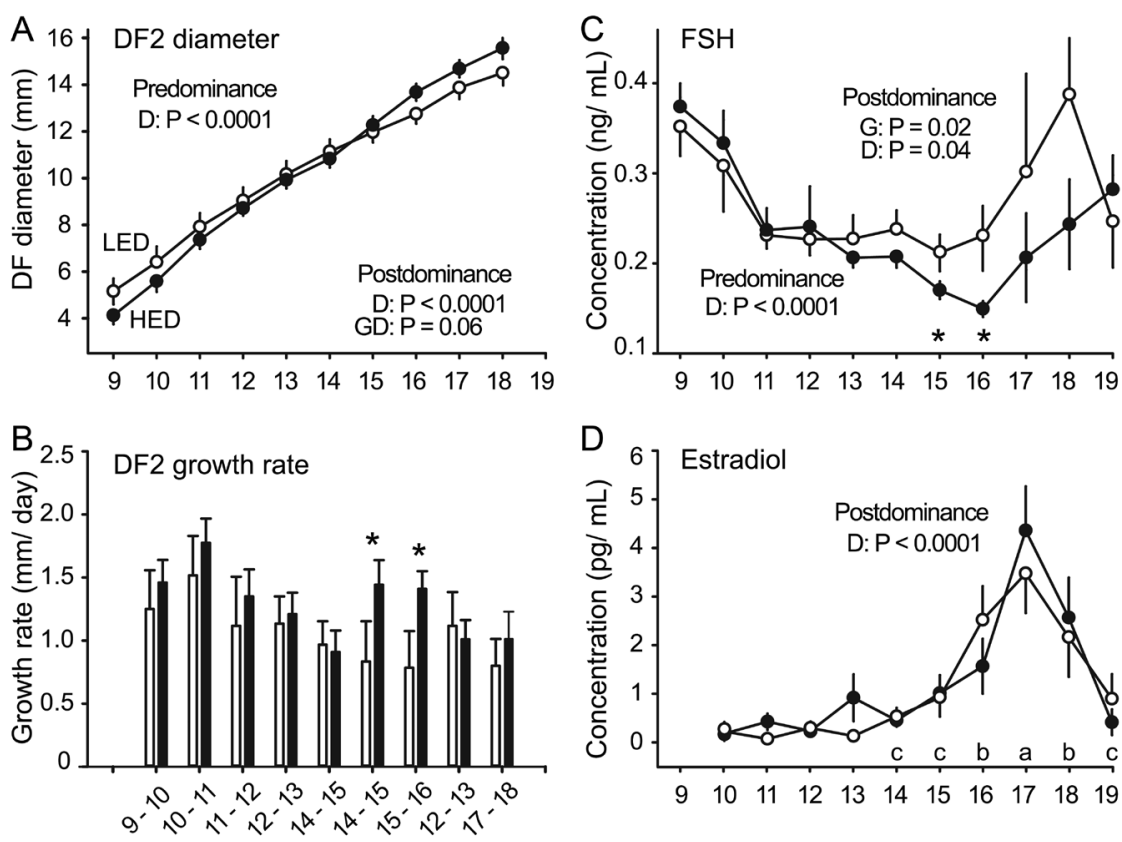

Days after ovulation

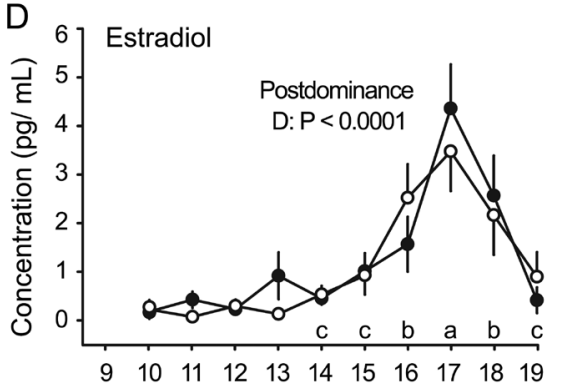

Days after ovulation
Figure 4 Mean \pm S.E.M. for diameter $(A)$ and growth rate $(\mathrm{B})$ of the ovulatory dominant follicle of wave 2 (DF2), and concentrations of $\mathrm{FSH}(\mathrm{C})$ and estradiol (D) during wave 2 for interovulatory interval (IOI) with two follicular waves in heifers fed low energy diet (LED; $n=6$ ) vs high energy diet (HED; $n=12$ ) throughout an IOI. Follicle diameter, concentrations of FSH and estradiol were evaluated during predominance (DF $<10 \mathrm{~mm}$; Days 9 to 13) and postdominance (DF $\geq 10$ $\mathrm{mm}$; Days 14 to 18 ) periods of wave two development. *Indicates difference $(P<0.05)$ between groups; ${ }^{a b c}$ means combined for groups with different letter are different $(P \leq 0.05)$ among Days. to comprehensively understand basic reproductive physiology and to rationally develop methods to improve reproductive efficiency in animals under different nutritional conditions. In the present study, we assessed the effects of nutrition, specifically energy, on follicle dynamics by increasing dietary energy throughout one full IOI. This study design provided a unique perspective on the interval between the increase in dietary energy content and detailed analysis of changes in follicle dynamics in heifers. The results supported the hypothesis that an acute increase in dietary energy (1) prolongs the growth period of dominant follicles and (2) alters the follicular wave pattern in heifers. Weight gains indicated that the supplementation of the concentrate promoted greater average daily gain for the HED compared to LED. The greater weight gains and the increased insulin concentrations in the HED heifers indicated that the concentrate supplement was effective in promoting physiologically relevant differences in the plane of nutrition.

In the present study, the effects of increased dietary energy were observed after a few days of treatment as shown by an increase in growth rate of DF1 within the first week of feeding HED. Other studies reported discreet or no effect of energy intake above maintenance requirements on follicular development even after several weeks of treatment (Murphy et al. 1991, Mackey et al. 2000). Murphy et al. (1991) reported no effect of dietary intake on follicle growth rate among heifers fed three different levels of dry matter intake, although shorter DF persistence was observed in restricted vs maintenancefed heifers, but similar DF persistence between heifers fed maintenance vs above maintenance levels. In the present study, HED had greater DF growth rate during wave 1 and during wave 2 in heifers with two-wave patterns. Additionally, the DF1 maintained dominance/ persistence for a longer time, as indicated by later reduction in DF1 growth rate and later DF1 regression. The greater DF1 growth rate in HED between Days 6 and 7 was primarily from maintenance of growth rate for one extra day compared with LED. During ovulatory wave 2, the greater growth rate of DF2 resulted in greater volume of the preovulatory follicle in HED than LED.

Nutrition impacts reproductive function in cattle by altering liver metabolism of steroids, by modulating concentrations of metabolic hormones (e.g. insulin, leptin, ghrelin) (Parr et al. 1993, Gong 2002, Wiltbank et al. 2006, Dupont et al. 2014), and by directly or indirectly altering hypothalamic/pituitary hormone secretion (Matthews et al. 2017, Cardoso et al. 2018). In previous studies, increased dry matter intake caused increased blood flow to the liver, which increased metabolism of steroids (Parr et al. 1993, Wiltbank et al. 2012, Ferraretto et al. 2014). In the present study, we observed no differences in circulating P4 during the IOI prior to luteolysis. Unfortunately, dry matter intake and liver blood flow were not measured. We speculate that lack of difference in P4 concentrations may be due to insufficient difference in the plane of nutrition and/or dry matter intake to alter liver blood flow and steroid metabolism. Therefore, it is more likely that the increased dietary energy affected follicular development by modulating concentrations of metabolic hormones and hypothalamic responsiveness to $\mathrm{P} 4$.

Several metabolic hormones in the systemic circulation and in the follicular fluid play a role in follicle development (Webb \& Armstrong 1998, Beg \& Ginther 2006, Dupont et al. 2014). Circulating insulin 

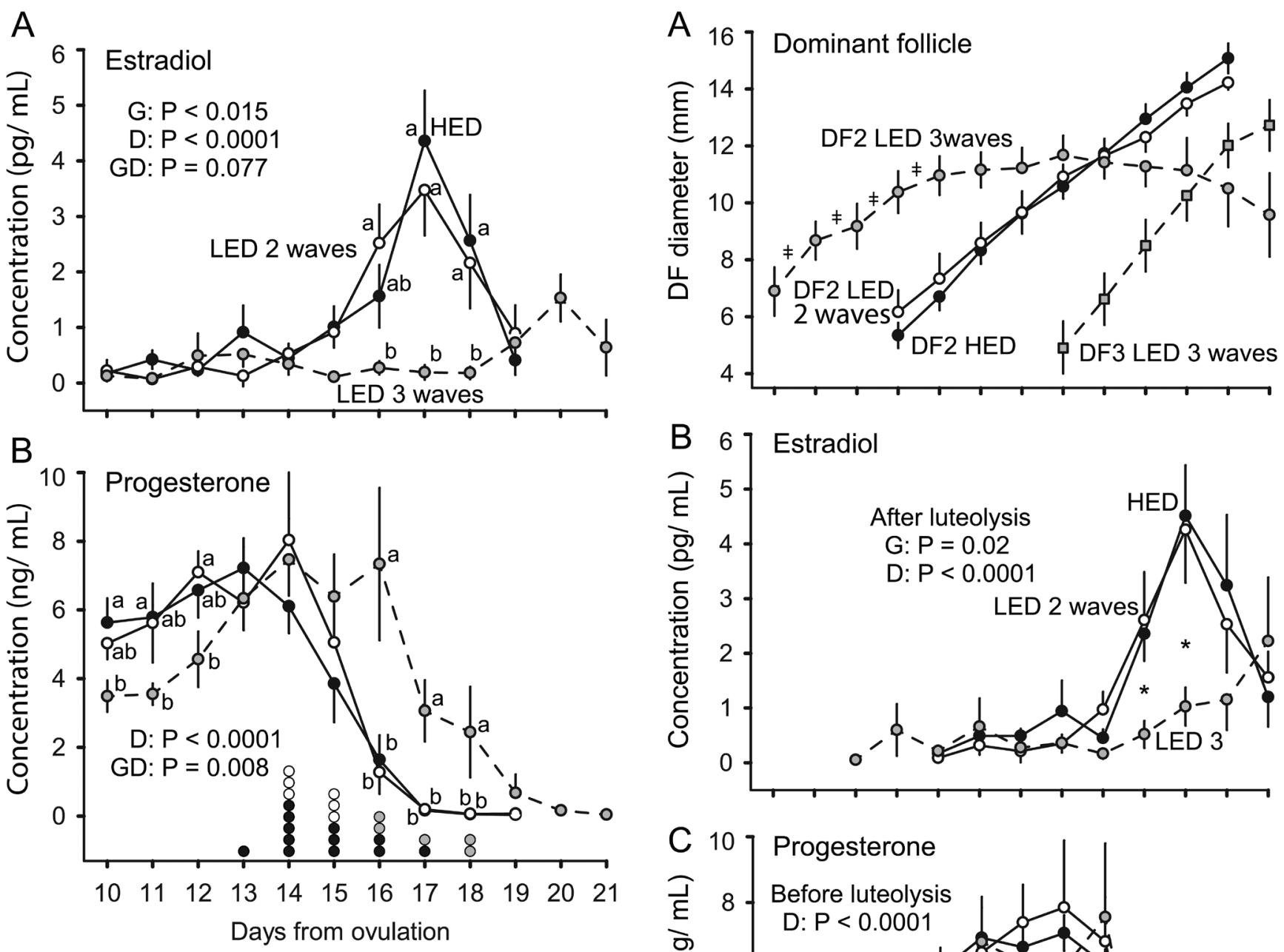

Figure 5 Mean \pm S.E.M. for concentrations of estradiol (A) and progesterone (B) during interovulatory interval (IOI) with two and three follicular waves for heifers fed low energy diet (LED; $n=6$ and 5 for two and three-wave patterns, respectively) vs high energy diet (HED; $n=12$ ) during an IOI. Individual scatter plot above the day axis indicates the day of beginning of luteolysis (day before $50 \%$ decrease in progesterone concentrations) for each heifer. ${ }^{\mathrm{ab}}$ Indicate a difference $(P \leq 0.05)$ among groups within a day.

and insulin-like growth factor 1 (IGF1) are known to increase during feeding of higher energy diets. Increased binding of insulin or IGF1 to their respective receptors in the granulosa cells could be directly enhancing follicle development (Garnsworthy et al. 2009, Dupont \& Scaramuzzi 2016). The effects of insulin on ovarian function have been extensively studied, especially in dairy cows, with increased systemic insulin favoring increased development of the dominant follicle and reducing the interval to first postpartum ovulation in high producing lactating cows (Gong et al. 2002b, Butler 2005). Additionally, insulin can enhance gonadotropin signaling thereby increasing aromatase activity in granulosa cells promoting granulosa cell proliferation (Spicer et al. 2002, Butler et al. 2004). Therefore, greater follicle growth rate during waves 1 and 2 in HED in the
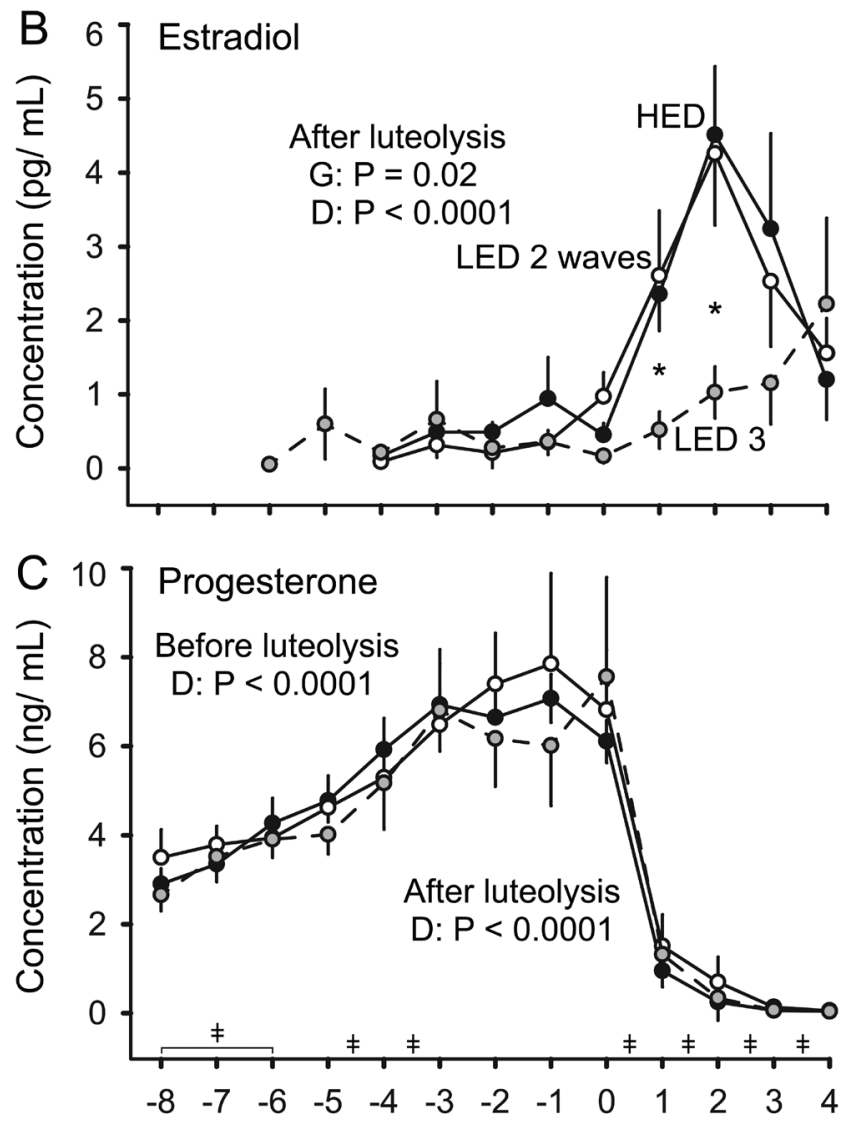

Days from beginning of luteolysis

Figure 6 Mean \pm S.E.M. for dominant follicles of waves two (DF2) and three (DF3) (A) and concentrations of estradiol (B) and progesterone (C) for heifers fed low energy diet (LED; $n=6$ and 5 for two and three-wave patterns, respectively) vs high energy diet (HED; $n=12$ ) during one interovulatory interval. Data were normalized to the beginning of luteolysis (day before $50 \%$ decrease in progesterone concentrations) and analyzed before (from 8 to 1 days before beginning of luteolysis) and after (days 0 to 4 ) the beginning of luteolysis. For anovulatory DF2 from LED there was a main effect of day $(P<0.0001)$. For the ovulatory follicles (DF2 from LED and HED with two waves and DF3 from LED with three waves) there were main effect of day $(P<0.01)$ and daily increase in follicle diameter. *Indicates a difference $(P \leq 0.05)$ among groups within a day; $¥$ indicates a difference $(P \leq 0.05)$ over days. 


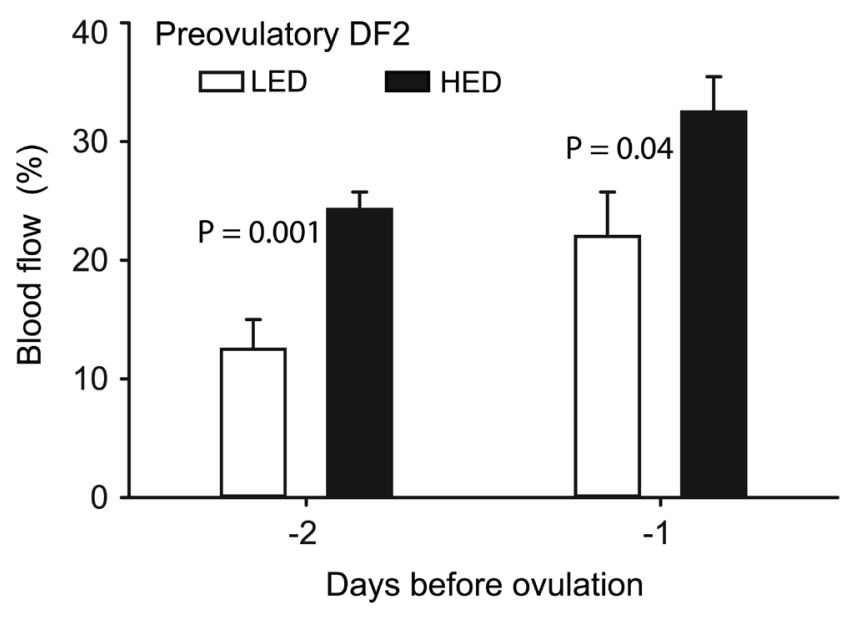

Figure 7 Mean \pm S.E.M for blood flow signals in the wall of the preovulatory dominant follicle of wave 2 in heifers fed low energy diet (LED) ( $n=6)$ vs high energy diet (HED) $(n=12)$ diets during one interovulatory interval.

present study may be related to the observed increase in insulin concentrations. Furthermore, the increased growth rate of DF2 and decreased FSH concentrations on Days 14 to 16 in HED coincide with the time of luteolysis in heifers with two follicular waves. Thus, increased cell proliferation and enhanced responsiveness to $\mathrm{LH}$ pulses, together with potentially enhanced GnRH/LH pulses (Ginther et al. 2012), likely led to greater number of granulosa cells with increased E2 production during a critical time period in wave 2, leading to activation of uterine E2 receptors and initiation of the luteolytic cascade, as discussed in detail below. Additionally, increased insulin may stimulate follicular E2 production and facilitates the earlier luteolysis that enables the high incidence of two follicular waves in HED. Moreover, increased insulin concentrations in HED may underlie the greater blood flow of the preovulatory follicle since insulin has proangiogenic activity in several tissues by increasing mRNA and protein levels of vascular endothelial growth factor (Escudero et al. 2017), a known intrafollicular factor associated with follicle vascularization (Beg \& Ginther 2006).

In the present study, as in several reports, three-wave patterns were associated with earlier emergence of wave 2, smaller maximal diameter of DF2, later luteal regression, and longer IOI (Fortune 1993, Jaiswal et al. 2009, Domingues et al. 2020). Because the number of follicular waves during an $\mathrm{IOI}$ and the timing of luteolysis are closely related (Ginther et al. 1989), we recently proposed a mechanism that encompasses adequate E2 concentrations and acquisition of endometrial responsiveness to $\mathrm{E} 2$ as determinants of the timing of luteolysis in heifers and the occurrence of two vs three follicular waves during an IOI (Domingues et al. 2020). In nonpregnant ruminants, luteal regression occurs due to pulsatile release of prostaglandin F2alpha (PGF) from the endometrium at the end of luteal phase (McCracken et al. 1999, Mezera et al. 2019). Initiation of PGF secretion involves E2 binding to the endometrial E2 receptor alpha causing upregulation of the oxytocin receptor which in turn triggers PGF synthesis and secretion (Lamming \& Mann 1995, Leung \& Wathes 2000, Araujo et al. 2009). Based on the mRNA concentrations of endometrial steroid receptors, acquisition of endometrial responsiveness to E2 occurs at a similar time (around 14-15 days after ovulation) in two and three-wave patterns following the downregulation of endometrial P4 receptor (Domingues et al. 2020). Downregulation of endometrial P4 receptor, a known inhibitor of E2 receptor alpha, occurs due to prolonged exposure to systemic P4 concentrations (Bishop 2013). In the present study, the frequency of two vs three follicular waves during the IOI was not associated with changes in systemic P4 concentrations before luteolysis, therefore, the dynamic expression of endometrial P4 receptor was presumably not altered. This suggests that the timing of luteolysis was hastened without changing the expression of endometrial P4 receptor which further supports the concept that all heifers acquire the uterine capacity of E2 receptor alpha responsiveness at about the same time regardless of the number of follicular waves. It seems likely that the ratelimiting step for timing of luteolysis is the production of E2 by DF2 and subsequent systemic E2 concentrations that could act on the endometrial E2 receptor alpha.

In the present study, it is clear that the initiation of luteal regression was temporally associated with increasing E2 concentrations. Normalization to the beginning of the $\mathrm{IOI}$ gives a unique perspective on the changes in concentrations of E2 (increase) related with the earlier luteolysis in two-wave patterns while the later increase in E2 concentrations in three-wave patterns were associated with later onset of luteal regression. The results of the present study further support the concept that the DF2 from two-wave patterns secretes adequate concentrations of E2 when the endometrial E2 receptor alpha becomes responsive to it, thereby initiating luteolysis (Araujo et al. 2009, Domingues et al. 2020). Alternatively, the DF2 from heifers with three-wave patterns is unable to trigger luteolysis and loses dominance (plateau of DF2 growth with limited E2 production) before activation of the endometrial mechanism for luteal regression. In three-wave patterns, luteolysis is delayed until adequate concentrations of E2 are produced during the third follicular wave. Normalization to the beginning of luteolysis emphasizes the distinct follicle dynamics and concentrations of E2 that are observed in two and three-wave patterns in relation with the onset of luteal regression. At the beginning of luteolysis in two-wave patterns, the DF2 was growing and secreting increasing concentrations of E2. Conversely, the DF2 of three-wave patterns reached a growth plateau (associated with low E2 concentrations) prior to initiation of luteolysis. In three-wave patterns, 
the DF3 secreted enough E2 to trigger luteolysis at a smaller diameter $(\sim 7 \mathrm{~mm})$ and E2 concentrations were clearly lower compared with two-wave patterns. The lower circulating E2 concentrations associated with luteolysis in three-wave patterns are consistent with the concept that the endometrium becomes more responsive (sensitive) to E2 later in the IOI (Domingues et al. 2020).

In an individual heifer, the repeatability of the number of follicular waves in two consecutive IOIs is about $70 \%$ (Jaiswal et al. 2009). Additionally, the frequency of two and three-wave patterns in a herd is similar within and between years (Ginther et al. 1989, Adams et al. 2008). By increasing the frequency of two-wave patterns in the HED, it becomes obvious that the dietary energy is a determining factor of the number of follicular waves during the IOI in heifers. Previous reports may have failed to clearly demonstrate this concept due to insufficient animal numbers and extended feeding protocols for multiple cycles prior to the investigated IOI (Murphy et al. 1991). It appears that an acute increase in energy diet resulted in greater incidence of two-wave patterns by increasing the growth rate and prolonging the growth period of DF1 and increasing the growth rate and steroidogenic capacity of DF2. The longer persistence of DF1 resulted in later emergence of wave 2. Additionally, increasing the growth rate of DF2 primarily during postdominance resulted in a growing DF2 that secretes adequate E2 when the endometrium becomes responsive to E2 thereby triggering luteolysis. Consequently, the growing DF2 became the ovulatory follicle. The findings presented herein provide a rationale for the variability in frequency of two vs threewave patterns in different herds and reports by different research groups since these patterns are, at least in part, influenced by the dietary energy content which may vary widely among studies (Ginther et al. 1989, Taylor \& Rajamahendran 1991, Fortune 1993, Noseir 2003).

The basic biological implications of energy-induced changes in follicular wave patterns are considerable, but there are also important practical implications for reproductive management of cattle. The fertility effects of two vs three-wave patterns are somewhat inconsistent with some studies indicating greater fertility in animals that ovulate a follicle from three than two follicular waves while other studies report no difference in fertility between two and three- wave animals (Ahmad et al. 1997, Townson et al. 2002, Bleach et al. 2004, Celik et al. 2005). Ovulation of follicles with longer periods of dominance (persistence) has been found to produce lower fertility, either under natural conditions (Austin et al. 1999, Bleach et al. 2004) or in model systems (Savio et al. 1993, Mihm et al. 1994, Ahmad et al. 1996), possibly due to ovulation of an overstimulated, aged oocyte (Revah \& Butler 1996). Thus, animals having a two-wave pattern may have a longer period of dominance and this could produce reduced fertility in cattle with two vs three- wave patterns. Additionally, the greater interval from the end of luteolysis to ovulation in three-wave patterns, as also observed in the present study, may result in a longer proestrus and lower $\mathrm{P} 4$ at the time of $\mathrm{Al} /$ ovulation which have been associated with greater fertility (Vasconcelos et al. 2013, Wiltbank et al. 2014a,b). On the contrary, a larger preovulatory follicle, as in two-wave patterns, would produce a larger $\mathrm{CL}$ and greater circulating P4 during the subsequent luteal phase (Vasconcelos et al. 2001) potentially increasing embryo elongation (Carter et al. 2008) and, if all else were equal, favoring improved fertility (Wiltbank et al. 2014b). One additional consideration is that the efficacy of protocols for synchronized ovulation may be changed by greater periods of follicular dominance, such as would be observed in cows with two follicular waves. For example, protocols that are initiated with GnRH treatment could have greater likelihood of ovulation, resulting in greater circulating P4 during ovulatory follicle growth and potentially greater fertility (Bello et al. 2006). Thus, in addition to potential direct effects of follicular wave patterns on fertility in cows that are bred after spontaneous estrus and ovulation, results could also be altered, in distinct ways, by energyinduced changes in follicular wave patterns in cows managed by synchronized ovulation and timed Al programs. Moreover, the results presented herein may serve as rationale for future studies to improve cattle management and reproductive efficiency by modulating the plane of nutrition and preovulatory follicle growth.

In conclusion, acute increase in dietary energy content caused dramatic changes in follicular dynamics in heifers. Increased dietary energy promoted longer persistence of the DF of wave 1 and increased the overall growth rate of the DF of waves 1 and 2. Altering follicle growth pattern resulted in altered follicular wave dynamics by increasing the frequency of two-wave patterns in heifers fed high energy diet.

\section{Declaration of interest}

The authors declare that there is no conflict of interest that could be perceived as prejudicing the impartiality of the research reported.

\section{Funding}

Funding was provided by the Eutheria Foundation as Project B2-RD-18 and by Hatch Project WIS01240 to M C W, and USDA-NIFA project 2019-67015-29704 to M C W.

\section{Author contribution statement}

R R D helped design the study, performed the study, analyzed the results, wrote original draft, and reviewed and edited the manuscript. O J G helped design the study, analyzed the results, supervised the research, and reviewed and edited the manuscript; and contributed. M Z T designed the study, 
reviewed and edited the manuscript. M C W helped design the study, analyzed the results, supervised the research, and reviewed and edited the manuscript; and contributed.

\section{Acknowledgment}

The authors would like to thank Victor Gomez-Leon for the assistance with the estradiol assay.

\section{References}

Adams GP, Matteri RL, Kastelic JP, Ko JC \& Ginther OJ 1992 Association between surges of follicle-stimulating hormone and the emergence of follicular waves in heifers. Journal of Reproduction and Fertility 94 177-188. (https://doi.org/10.1530/jrf.0.0940177)

Adams GP, Jaiswal R, Singh J \& Malhi P 2008 Progress in understanding ovarian follicular dynamics in cattle. Theriogenology 69 72-80. (https:// doi.org/10.1016/j.theriogenology.2007.09.026)

Ahmad N, Beam SW, Butler WR, Deaver DR, Duby RT, Elder DR, Fortune JE, Griel LC, Jones LS, Milvae RA et al. 1996 Relationship of fertility to patterns of ovarian follicular development and associated hormonal profiles in dairy cows and heifers. Cooperative Regional Research Project. Journal of Animal Science 74 1943-1952. (https://doi. org/10.2527/1996.7481943x)

Ahmad N, Townsend EC, Dailey RA \& Inskeep EK 1997 Relationships of hormonal patterns and fertility to occurrence of two or three waves of ovarian follicles, before and after breeding, in beef cows and heifers. Animal Reproduction Science 49 13-28. (https://doi.org/10.1016/s03784320(97)00057-2)

Araujo RR, Ginther OJ, Ferreira JC, Palhao MM, Beg MA \& Wiltbank MC 2009 Role of follicular estradiol-17beta in timing of luteolysis in heifers. Biology of Reproduction 81 426-437. (https://doi.org/10.1095/ biolreprod.108.073825)

Austin EJ, Mihm M, Ryan MP, Williams DH \& Roche JF 1999 Effect of duration of dominance of the ovulatory follicle on onset of estrus and fertility in heifers. Journal of Animal Science 77 2219-2226. (https://doi. org/10.2527/1999.7782219x)

Beg MA \& Ginther OJ 2006 Follicle selection in cattle and horses: role of intrafollicular factors. Reproduction 132 365-377. (https://doi. org/10.1530/rep.1.01233)

Bello NM, Steibel JP \& Pursley JR 2006 Optimizing ovulation to first GnRH improved outcomes to each hormonal injection of Ovsynch in lactating dairy cows. Journal of Dairy Science 89 3413-3424. (https:// doi.org/10.3168/jds.S0022-0302(06)72378-5)

Bishop CV 2013 Progesterone inhibition of oxytocin signaling in endometrium. Frontiers in Neuroscience 7 138. (https://doi.org/10.3389/ fnins.2013.00138)

Bleach ECL, Glencross RG \& Knight PG 2004 Association between ovarian follicle development and pregnancy rates in dairy cows undergoing spontaneous oestrous cycles. Reproduction 127 621-629. (https://doi. org/10.1530/rep.1.00190)

Butler WR 2005 Nutrition, negative energy balance and fertility in the postpartum dairy cow. Cattle Practice 13 13-18.

Butler ST, Pelton SH \& Butler WR 2004 Insulin increases 17 beta-estradiol production by the dominant follicle of the first postpartum follicle wave in dairy cows. Reproduction 127 537-545. (https://doi.org/10.1530/ rep.1.00079)

Cardoso RC, Alves BRC \& Williams GL 2018 Neuroendocrine signaling pathways and the nutritional control of puberty in heifers. Animal Reproduction 15 868-878. (https://doi.org/10.21451/1984-3143AR2018-0013)

Carter F, Forde N, Duffy P, Wade M, Fair T, Crowe MA, Evans AC, Kenny DA, Roche JF \& Lonergan P 2008 Effect of increasing progesterone concentration from day 3 of pregnancy on subsequent embryo survival and development in beef heifers. Reproduction, Fertility, and Development 20 368-375. (https://doi.org/10.1071/rd07204)

Celik HA, Aydin I, Sendag S \& Dinc DA 2005 Number of follicular waves and their effect on pregnancy rate in the cow. Reproduction in Domestic Animals 40 87-92. (https://doi.org/10.1111/j.1439-0531.2004.00516.x)
Domingues RR, Ginther OJ, Gomez-León VE \& Wiltbank MC 2020 Upregulation of endometrial oxytocin receptor is associated with the timing of luteolysis in heifers with two and three follicular waves. Biology of Reproduction 102 316-326. (https://doi.org/10.1093/biolre/ioz165)

Dupont J \& Scaramuzzi RJ 2016 Insulin signalling and glucose transport in the ovary and ovarian function during the ovarian cycle. Biochemical Journal 473 1483-1501. (https://doi.org/10.1042/BCJ20160124)

Dupont J, Scaramuzzi RJ \& Reverchon M 2014 The effect of nutrition and metabolic status on the development of follicles, oocytes and embryos in ruminants. Animal 8 1031-1044. (https://doi.org/10.1017/ S1751731114000937)

Escudero CA, Herlitz K, Troncoso F, Guevara K, Acurio J, Aguayo C, Godoy AS \& Gonzalez M 2017 Pro-angiogenic role of insulin: from physiology to pathology. Frontiers in Physiology 8 204. (https://doi. org/10.3389/fphys.2017.00204)

Ferguson JD, Galligan DT \& Thomsen N 1994 Principal descriptors of body condition score in Holstein cows. Journal of Dairy Science 77 2695-2703. (https://doi.org/10.3168/jds.S0022-0302(94)77212-X)

Ferraretto LF, Gencoglu H, Hackbart KS, Nascimento AB, Dalla Costa F, Bender RW, Guenther JN, Shaver RD \& Wiltbank MC 2014 Effect of feed restriction on reproductive and, metabolic hormones in dairy cows. Journal of Dairy Science 97 754-763. (https://doi.org/10.3168/jds.20136925)

Forde N, Beltman ME, Lonergan P, Diskin M, Roche JF \& Crowe MA 2011 Oestrous cycles in Bos taurus cattle. Animal Reproduction Science 124 163-169. (doi:10.1016/j.anireprosci.2010.08.025)

Fortune JE 1993 Follicular dynamics during the bovine estrous cycle: a limiting factor in improvement of fertility? Animal Reproduction Science 33 111-125. (https://doi.org/10.1016/0378-4320(93)90110-D)

Garnsworthy PC, Fouladi-Nashta AA, Mann GE, Sinclair KD \& Webb R 2009 Effect of dietary-induced changes in plasma insulin concentrations during the early post partum period on pregnancy rate in dairy cows. Reproduction 137 759-768. (https://doi.org/10.1530/REP-08-0488)

Ginther OJ 1998 Ultrasonic Imaging and Animal Reproduction: Cattle. Wisconsin: Equiservices Publishing.

Ginther OJ 2007 Ultrasoninc Imaging and Animal Reproduction: ColorDoppler Ultrasonography. Wisconsin: Equiservices Publishing.

Ginther OJ 2016 The theory of follicle selection in cattle. Domestic Animal Endocrinology $57 \quad$ 85-99. (https://doi.org/10.1016/j. domaniend.2016.06.002)

Ginther OJ, Knopf L \& Kastelic JP 1989 Temporal associations among ovarian events in cattle during oestrous cycles with two and three follicular waves. Journal of Reproduction and Fertility 87 223-230. (https://doi.org/10.1530/jrf.0.0870223)

Ginther OJ, Khan FA, Hannan MA, Rodriguez MB, Pugliesi G \& Beg MA 2012 Role of LH in luteolysis and growth of the ovulatory follicle and estradiol regulation of $\mathrm{LH}$ secretion in heifers. Theriogenology 77 1442-1452. (https://doi.org/10.1016/j.theriogenology.2011.11.014)

Ginther OJ, Bashir ST, Rakesh HB \& Hoffman MM 2013 Two-way coupling between FSH and the dominant follicle in heifers. Theriogenology $\mathbf{8 0}$ 463-469. (https://doi.org/10.1016/j.theriogenology.2013.05.008)

Gomez-Leon VE, Ginther OJ, Araujo ER, Guimaraes JD \& Wiltbank MC 2019 Hormonal mechanisms regulating follicular wave dynamics I: comparison of follicle growth profiles under different physiological conditions in heifers. Theriogenology 123 194-201. (https://doi. org/10.1016/j.theriogenology.2018.09.006)

Gomez-León VE, Ginther OJ, Domingues RR, Guimarães JD \& Wiltbank MC 2020 Necessity for LH in selection and continued growth of the bovine dominant follicle. Reproduction 159 559-569. (https://doi. org/10.1530/REP-19-0342)

Gong JG 2002 Influence of metabolic hormones and nutrition on ovarian follicle development in cattle: practical implications. Domestic Animal Endocrinology 23 229-241. (https://doi.org/10.1016/s07397240(02)00159-5)

Gong JG, Armstrong DG, Baxter G, Hogg CO, Garnsworthy PC \& Webb R 2002a The effect of increased dietary intake on superovulatory response to FSH in heifers. Theriogenology 57 1591-1602. (https://doi. org/10.1016/s0093-691x(02)00668-4)

Gong JG, Lee WJ, Garnsworthy PC \& Webb R 2002b Effect of dietaryinduced increases in circulating insulin concentrations during the early postpartum period on reproductive function in dairy cows. Reproduction 123 419-427. (https://doi.org/10.1530/rep.0.1230419) 
Jaiswal RS, Singh J, Marshall L \& Adams GP 2009 Repeatability of 2-wave and 3-wave patterns of ovarian follicular development during the bovine estrous cycle. Theriogenology 72 81-90. (https://doi.org/10.1016/j. theriogenology.2009.02.014)

Lamming GE \& Mann GE 1995 Control of endometrial oxytocin receptors and prostaglandin F2 alpha production in cows by progesterone and oestradiol. Journal of Reproduction and Fertility 103 69-73. (https://doi. org/10.1530/jrf.0.1030069)

Leung ST \& Wathes DC 2000 Oestradiol regulation of oxytocin receptor expression in cyclic bovine endometrium. Journal of Reproduction and Fertility 119 287-292.

Mackey DR, Wylie ARG, Sreenan JM, Roche JF \& Diskin MG 2000 The effect of acute nutritional change on follicle wave turnover, gonadotropin, and steroid concentration in beef heifers. Journal of Animal Science $\mathbf{7 8}$ 429-442. (https://doi.org/10.2527/2000.782429x)

Matthews D, Diskin MG, Kenny DA, Creevey CJ, Keogh K \& Waters SM 2017 Effect of short term diet restriction on gene expression in the bovine hypothalamus using next generation RNA sequencing technology. BMC Genomics 18 857. (https://doi.org/10.1186/s12864-017-4265-6)

McCracken JA, Custer EE \& Lamsa JC 1999 Luteolysis: a neuroendocrinemediated event. Physiological Reviews 79 263-323. (https://doi. org/10.1152/physrev.1999.79.2.263)

Mezera MA, Hamm CS, Gamarra CA, Gennari RS, Prata AB, Sartori R \& Wiltbank MC 2019 Profiles of prostaglandin F-2 alpha metabolite in dairy cattle during luteal regression and pregnancy: implications for corpus luteum maintenance. Biology of Reproduction 101 76-90. (https://doi.org/10.1093/biolre/ioz074)

Mihm M, Baguisi A, Boland MP \& Roche JF 1994 Association between the duration of dominance of the ovulatory follicle and pregnancy rate in beef heifers. Journal of Reproduction and Fertility 102 123-130. (https:// doi.org/10.1530/jrf.0.1020123)

Murphy MG, Enright WJ, Crowe MA, Mcconnell K, Spicer LJ, Boland MP \& Roche JF 1991 Effect of dietary intake on pattern of growth of dominant follicles during the oestrous cycle in beef heifers. Journal of Reproduction and Fertility 92 333-338. (https://doi.org/10.1530/jrf.0.0920333)

Noseir WM 2003 Ovarian follicular activity and hormonal profile during estrous cycle in cows: the development of 2 versus 3 waves. Reproductive Biology and Endocrinology 1 50. (https://doi.org/10.1186/14777827-1-50)

Parr RA, Davis IF, Miles MA \& Squires TJ 1993 Liver blood flow and metabolic clearance rate of progesterone in sheep. Research in Veterinary Science 55 311-316. (https://doi.org/10.1016/0034-5288(93)90100-t)

Revah I \& Butler WR 1996 Prolonged dominance of follicles and reduced viability of bovine oocytes. Journal of Reproduction and Fertility $\mathbf{1 0 6}$ 39-47. (https://doi.org/10.1530/jrf.0.1060039)

Rhodes FM, Fitzpatrick LA, Entwistle KW \& Death G 1995 Sequential changes in ovarian follicular dynamics in Bos indicus heifers before and after nutritional anoestrus. Journal of Reproduction and Fertility 104 41-49. (https://doi.org/10.1530/jrf.0.1040041)

Sartori R, Fricke PM, Ferreira JCP, Ginther OJ \& Wiltbank MC 2001 Follicular deviation and acquisition of ovulatory capacity in bovine follicles. Biology of Reproduction 65 1403-1409. (https://doi. org/10.1095/biolreprod65.5.1403)

Sartori R, Guardieiro MM, Surjus RS, Melo LF, Prata AB, Ishiguro $M$, Bastos MR \& Nascimento AB 2013 Metabolic hormones and reproductive function in cattle. Animal Reproduction 10 199-205.
Savio JD, Thatcher WW, Morris GR, Entwistle K, Drost M \& Mattiacci MR 1993 Effects of induction of low plasma progesterone concentrations with a progesterone-releasing intravaginal device on follicular turnover and fertility in cattle. Journal of Reproduction and Fertility 98 77-84. (https://doi.org/10.1530/jrf.0.0980077)

Spicer LJ, Chamberlain CS \& Maciel SM 2002 Influence of gonadotropins on insulin- and insulin-like growth factor-I (IGF-I)-induced steroid production by bovine granulosa cells. Domestic Animal Endocrinology 22 237-254. (https://doi.org/10.1016/s0739-7240(02)00125-x)

Taylor C \& Rajamahendran R 1991 Follicular dynamics, corpus luteum growth and regression in lactating dairy cattle. Canadian Journal of Animal Science 71 61-68. (https://doi.org/10.4141/cjas91-007)

Townson DH, Tsang PCW, Butler WR, Frajblat M, Griel LC, Johnson CJ, Milvae RA, Niksic GM \& Pate JL 2002 Relationship of fertility to ovarian follicular waves before breeding in dairy cows. Journal of Animal Science 80 1053-1058. (https://doi.org/10.2527/2002.8041053x)

Vasconcelos JLM, Sartori R, Oliveira HN, Guenther JG \& Wiltbank MC 2001 Reduction in size of the ovulatory follicle reduces subsequent luteal size and pregnancy rate. Theriogenology 56 307-314. (https://doi. org/10.1016/s0093-691x(01)00565-9)

Vasconcelos JLM, Pereira MHC, Meneghetti M, Dias CC, Sa OG, Peres RFG, Rodrigues ADP \& Wiltbank MC 2013 Relationships between growth of the preovulatory follicle and gestation success in lactating dairy cows. Animal Reproduction 10 206-214.

Webb R \& Armstrong DG 1998 Control of ovarian function; effect of local interactions and environmental influences on follicular turnover in cattle: a review. Livestock Production Science 53 95-112. (https://doi. org/10.1016/S0301-6226(97)00161-9)

Wiltbank M, Lopez H, Sartori R, Sangsritavong S \& Gumen A 2006 Changes in reproductive physiology of lactating dairy cows due to elevated steroid metabolism. Theriogenology 65 17-29. (https://doi. org/10.1016/j.theriogenology.2005.10.003)

Wiltbank MC, Souza AH, Giordano JO, Nascimento AB, Vasconcelos JM, Pereira MHC, Fricke PM, Surjus RS, Zinsly FCS, Carvalho PD et al. 2012 Positive and negative effects of progesterone during timed Al protocols in lactating dairy cattle. Animal Reproduction 9 231-241.

Wiltbank MC, Baez GM, Vasconcelos JLM, Pereira M, Souza AH, Sartori R \& Pursley JR 2014a The physiology and impact on fertility of the period of proestrus in lactating dairy cows. Animal Reproduction 11 225-236.

Wiltbank MC, Souza AH, Carvalho PD, Cunha AP, Giordano JO, Fricke PM, Baez GM \& Diskin MG 2014b Physiological and practical effects of progesterone on reproduction in dairy cattle. Animal 8 (Supplement 1) 70-81. (https://doi.org/10.1017/S17517311 14000585)

Received 1 July 2020

First decision 3 August 2020

Revised Manuscript received 28 August 2020

Accepted 15 September 2020 